\title{
QUATERNARY BURIED CHANNELS IN NORTH GERMANY
}

\author{
Jürgen Ehlers \\ Geologisches Landesamt, Billstr. 84. 20539 Hamburg, Germany
} e-mail: Juergen.Ehlers@bsu.hamburg.de

The southern peripheral zone of the North European ice sheets is characterised by a network-like systems of channels, running mostly in a radial pattern from the centre of glaciation to the former ice margins. In contrast to the most recent channels formed during the last ice age which are still clearly visible at the land surface, the Elsterian channels have been completely filled. In the literature these forms are often referred to as tunnel valleys, because they were formed by meltwater flowing through tunnels underneath the ice. Tunnel channels might be a more appropriate term, as in contrast to normal valleys their thalweg has no continuous unidirectional gradient.

Modern geological investigation of the tunnel channels in Europe was initiated in East Germany. The first detailed investigations of Ice Age channel patterns were made by Eissmann (1975). In some cases the course of the channels could be traced for many kilometres in the open-cast lignite mines in the Leipzig area. The depths of the channels vary greatly. In Northern Germany, a maximum depth of $434 \mathrm{~m}$ b.s.l. was found for the Elsterian Reeßelner Rinne. Equally, in the Southern North Sea, maximum depths of channels of more than $400 \mathrm{~m}$ b.s.l. have been measured. Channel courses can be locally influenced by deep-seated tectonics. This is most obvious in the case of the so-called Alnarp Valley, a trough following the margin of the Fennoscandian Shield through Skåne (southern Sweden) and northern Denmark. In addition, channel courses can be influenced by the strike directions of salt domes, as demonstrated by Piotrowski (1994) in Schleswig-Holstein.

The intensity of channel formation varied through space and time during all ice ages. Yet these differences do not apply everywhere. Seismic investigations in the North Sea have revealed that channels there formed at least during three glaciations (e.g. Ehlers \& Wingfield 1991). In the southern part of the North Sea the oldest channel system is most strongly pronounced. The same may be true of the German and Danish sectors (Schwarz, 1996; Huuse \& Lykke-Andersen, 2000). In the British sector of the central North Sea, however, the deepest forms relate to the last, Weichselian Stage.

Although on land a regular U-shaped profile has generally been suggested for the reconstruction of Elsterian channels, evaluation of seismic profiles from the North Sea shows this form is rather the exception. Only about one third of the deep incisions have a simple U-profile, whereas the rest shows much more complicated cross profiles (Ehlers 1990). Detailed seismic investigations have shown that channels often consist of a system of parallel incisions. This indicates that the channels were not generated in a single process, but through a sequence of several similar events. Occasional reactivations of old, abandoned channels during later glaciations are known. The shape of the channels, with their local overdeepenings and irregularities of profile, definitely excludes extra-glacial formation, such as river valleys. In most examples subglacial meltwater erosion was the main force behind the channel formation.

When the Elsterian ice melted, large ice-dammed lakes formed in which silt and clay were deposited. In North Germany these glaciolacustrine deposits are called 'Lauenburger Ton' (Lauenburg Clay). Their distribution reaches west into the Netherlands, where this sediment is referred to as 'potklei' (pottery clay) in the Provinces of Friesland, Groningen, and Drente. It consists of a complex of glaciolacustrine clays, silts, and fine sands; in the channels it can reach a thickness of over $150 \mathrm{~m}$. The composition of the Lauenburg Clay reflects the progressive decay of the Elsterian ice. Whereas the older layers are rich in dropstones and mixed with sand, the sorting increases towards the top where a sequence of laminated sediments is found. If they represent annual layering, deposition in the Hamburg region seems to have lasted for more than 2000 years. As the channels are not visible on the surface, their reconstruction relies on borehole records and geophysical investigations. In the BurVal project, geologists from Denmark, the Netherlands and North Germany worked together to improve the understanding of those features. 3D modelling is used to improve the understanding of the irregularly shaped buried channels. 